\title{
Introduction to the panel on Biotechnology Research and Development in Industry Rania Siam ${ }^{1,2,3}$
}

\author{
Address: ${ }^{1}$ Biotechnology Graduate Program, American University in Cairo, Cairo, Egypt, ${ }^{2}$ Biology Department, American University in Cairo, \\ Cairo, Egypt and ${ }^{3}$ YJ-Science and Technology Research Center, American University in Cairo, Cairo, Egypt \\ from 2009 American University in Cairo Research Conference \\ Cairo, Egypt. 5 April 2009
}

Published: I July 2009

BMC Proceedings 2009, 3(Suppl 3):OI

This abstract is available from: http://www.biomedcentral.com/I753-656I/3/S3/OI

(c) 2009 Siam; licensee BioMed Central Ltd.

Biotechnology is a cutting edge interdisciplinary field combining the expertise of personnel in different fields from biology, chemistry, and physics to math and engineering to contribute extensively to pharmaceutics, diagnostics, medical, agriculture and the environment. Several Biotechnology hotbeds exist in North America from the southern Biotech Bay, Biotech Beach to the eastern coast Genetown and the northern BioCanada; which encompass the biotechnology, pharmaceutical and medical device industries in this region. The EU Biotech is another advanced biotechnology hotbed community and is believed to be a "world leader" in biotechnology and pharmaceutical research and development. AsiaBio is another proven biotechnology hotbed that has successfully competed in the biotechnology field internationally. These hotbed communities have contributed to the fact the biotechnology is one of the most recognized applied science of the $21^{\text {st }}$ century. Egypt is part of the AfriBio biotechnology community.

The focus of our panel is to address and discuss the biotechnology research and development in Egypt. This will be addressed by looking into a few examples on ongoing research in Egypt. 